\title{
DE VERMOGENSSTRUCTUUR VAN DE ONDERNEMING
}

\author{
door Dr. M. J. L. Jonkhart
}

\section{Inleiding}

Een goochelaar kan een konijn pas dan uit een hoed laten komen wanneer hij het eerst al dan niet ongemerkt - zelf in de hoed heeft gestopt. Deze gedachte kwam bij mij op toen de redactie mij vroeg een bijdrage te schrijven naar aanleiding van het verschijnen van mijn proefschrift [6]. Het probleem van de goochelaar vertoont immers grote overeenkomst met de moderne theorievorming rond de vermogensstructuur van de onderneming. Evenals bij de goochelaar is het beoogde resultaat bekend: uit de hoed moeten extremen van functies tevoorschijn komen, zodat de hoed zelf op de een of andere wijze marginale kosten en marginale opbrengsten zal moeten bevatten die dan vervolgens aan elkaar gelijk gesteld kunnen worden. Maar welke kosten en opbrengsten en hoe komen ze op tijd in de hoed? In mijn proefschrift is dan ook allereerst een belangrijke plaats ingeruimd voor het zoeken naar een zo eenvoudig mogelijke afleiding van de in de literatuur bekende resultaten en het achterhalen van de minst restrictieve veronderstellingen waaronder deze resultaten opgeld blijven doen. Vervolgens wordt een poging gedaan de benaderingen met betrekking tot de optimale vermogensstructuur en de leencapaciteit zoals die in de literatuur worden gepresenteerd met elkaar in verband te brengen om van daaruit de lijnen te schetsen waarlangs een verdere uitbouw aan de theorie zou kunnen worden gegeven.

In het bestek van deze bijdrage zou het te ver voeren het gehele geschrift de revue te laten passeren. Daarom zal in het hierna volgende slechts een beperkt aantal aspecten uit de materie worden gelicht, waarbij de keuze met name is gevallen op een aantal achter de theorie liggende en zelden of nooit geëxpliciteerde veronderstellingen die nauw samenhangen met het wanbetalingsrisico van de verschaffers van het niet-ondernemend vermogen. Allereerst zal echter het neo klassieke basismodel van de vermogensstructuur zoals dat in [6] nader wordt uitgewerkt, kort worden weergegeven.

\section{Basismodel}

Uitgegaan wordt van een situatie waarin ondernemingen aan belasting onderworpen zijn en waarin faillissement kosten met zich meebrengt. Faillissement - in economische zin - wordt daarbij gedefinieerd als de situatie waarin de onderneming niet aan haar betalingsverplichtingen jegens haar schuldeisers kan voldoen. In het kader van het in het hierna volgende te hanteren één-periode model treedt faillissement derhalve op wanneer 
waarbij

$\widetilde{\mathrm{X}}=$ de onzekere opbrengst die aan het einde van de periode door de activa van de onderneming gegenereerd blijkt te zijn en wel vóór aftrek van be. lasting,

$\widehat{Y}=$ de contractueel met de schuldeisers van de onderneming overeengeko. men betaling aan het einde van de periode; $\hat{Y}$ bestaat dus zowel uit rente als uit aflossing.

Er zijn geen (verstorende) imperfecties anders dan de hier expliciet genoemde. Tenslotte wordt aangenomen dat de onderneming streeft naar welvaarts. maximalisatie van de bestaande aandeelhouders. Aangetoond kan worden dat dit doel onder de hier genoemde veronderstellingen equivalent is met het ma. ximaliseren van de marktwaarde van de onderneming.

De marktwaarde van de onderneming (V) laat zich nu bepalen als

$\mathrm{V}=\mathrm{V}_{\mathrm{u}}+\tau \mathrm{B}-\mathrm{C}$

waarbij

$\mathrm{V}_{\mathrm{u}}=$ de waarde van de onderneming wanneer zij geheel met ondernemend vermogen gefinancierd zou zijn,

$\mathrm{B}=$ de marktwaarde van het niet-ondernemend vermogen,

$\tau=$ de gemiddelde en tevens marginale belastingquote,

$\tau \mathrm{B}=$ de martkwaarde van de belastingbesparing die wordt verkregen als ge. volg van het financieren met niet-ondernemend vermogen,")

$\mathrm{C}=$ de contante waarde van de kosten die met een faillissement gepaard gaan.

Thans is de basis gelegd voor een drietal proposities ten aanzien van de ver. mogensstructuur.

Propositie 1: De optimale vermogensstructuur, d.w.z. de vermogensstructuur die de waarde van de onderneming voor de bestaande aandeelhouders maximaliseert, gegeven $\widetilde{\mathrm{X}}$, wordt bereikt wanneer de contante waarde van de mar. ginale belastingbesparingen gelijk is aan de contante waarde van de marginale faillissementskosten.

Bewijs: Differentiatie van (2) naar $\hat{\mathrm{Y}}$ als de bepalende factor voor de mate waar. in met niet-ondernemend vermogen wordt gefinancierd, levert:

$\frac{\partial \mathrm{V}}{\partial \hat{\mathrm{Y}}}=\tau \frac{\partial \mathrm{B}}{\partial \hat{\mathrm{Y}}}-\frac{\partial \mathrm{C}}{\partial \hat{\mathrm{Y}}}$

\footnotetext{
1) Opgemerkt dient te worden dat de term $\tau$ B zeer specifieke eisen stelt aan het aan het model ten grondslag liggende belastingregime. Voor een nadere uiteenzeting van deze problematiek zij verwezen naar [6], m.n. pag. 17 18, pag. 23.24 alsmede pag. 32
} 
hetgeen nul is wanneer de waarde van de marginale belastingbesparing gelijk is aan de waarde van de marginale faillissementskosten. ${ }^{2}$ )

Propositie 2: De optimale vermogensstructuur wordt bereikt vóór de leencapaciteit, gedefinieerd als het maximale bedrag aan niet-ondernemend vermogen dat de vermogensmarkt op een gegeven moment bereid is ter beschikking te stellen van een onderneming met een gegeven samenstel van activa.

Bewijs: Bij het bereiken van het optimum in de vermogensstructuur zal gelden dat $\tau \frac{\partial \mathrm{B}}{\partial \hat{\mathrm{Y}}}=\frac{\partial \mathrm{C}}{\partial \hat{\mathrm{Y}}}$. Gezien het feit dat $\frac{\partial \mathrm{C}}{\partial \hat{\mathrm{Y}}}$ altijd positief is (tenzij men bereid is te veronderstellen dat er "states of nature” met negatieve faillissementskosten bestaan), zal op dit punt tevens gelden dat $\frac{\frac{\partial \mathrm{B}}{\mathrm{B}}}{\partial \hat{\mathrm{Y}}}>0$.

Propositie 3: De leencapaciteit wordt bereikt voordat faillissement zeker is ge. worden, dat wil zeggen voordat de vermogensstructuur geheel uit niet-onder. nemend vermogen bestaat.

Bewijs: Uit de definitievergelijking $B=V-S$, waarbij $S$ de marktwaarde van het ondernemend vermogen voorstelt, volgt na differentiatie en na substitutie van (3):

$(1-\tau) \frac{\partial B}{\partial \hat{Y}}=-\frac{\partial S}{\partial \hat{Y}}-\frac{\partial C}{\partial \hat{Y}}$

Ten tijde van het bereiken van de leencapaciteit zal moeten gelden dat $\frac{\partial B}{\partial \hat{Y}}=0$. Omdat $\frac{\partial C}{\partial \hat{Y}}$ altijd positief is, zal op dit punt $\frac{\partial S}{\partial \hat{Y}}$ negatief moeten zijn. Dit betekent dat een verdere vergroting van $\hat{Y}$ zal resulteren in een ver. dere daling van $S$, hetgeen alleen mogelijk is indien $S$ zelf strict positief is. Dit laatste wijst er op zijn beurt weer op dat faillissement nog niet zeker is.

Met behulp van de voorgaande drie proposities laat zich een afgeronde voorstelling van zaken maken. De optimale vermogensstructuur wordt bereikt vóór de leencapaciteit die op zijn beurt wordt bereikt voordat faillissement zeker is

\footnotetext{
3) Dat er inderdaad sprake is van een maximum, laat zich als volgi inzien. Bij een bescheiden gebruik van niet onder nemend vermogen zal een toename van $Y$ resulteren in een stijging van rowel $+\mathrm{H}$ als $\mathrm{C}$. Bewezen kan worden dat het saldo positief is, zodat $\mathrm{V}$ op dit punt stijgende is. Bij een hoge mate van "financial leverage" zal $\mathrm{C}$ nog steeds stijgen terwijl (zie propositie 3 ) bewezen kan worden dat $; \mathbf{k}$ zal gaan dalen voordat faillissement zeker is geworden. Een verdere vergro. ting van $\hat{Y}$ zal derhalve nu resulteren in een daling van $V$. Een en ander impliceert dat $V$ als tunctie van $\hat{Y}$ een maximum moet zijn gepasseerd.
} 
geworden. Derhalve zal de optimale vermogensstructuur evenmin voor de volle honderd procent uit niet-ondernemend vermogen bestaan. Een en ander impliceert dat de vermogensmarkt bereid is het de marktwaarde van de onderneming maximaliserende bedrag aan niet-ondernemend vermogen ter be schikking te stellen en zelfs meer dan dat. Anderzijds zal de onderneming er goed aan doen haar leenmogelijkheden niet ten volle uit te putten. Figuur 1 geeft de voorgaande conclusie nog eens grafisch weer.

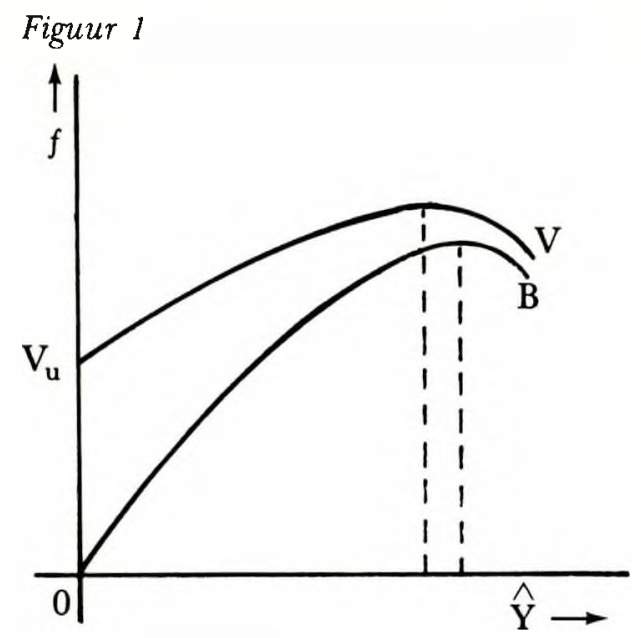

\section{Veronderstellingen}

De problemen van het model blijken zich in hoofdzaak te concentreren op de equivalentie van het maximaliseren van de waarde van de onderneming en het maximaliseren van de welvaart van de bestaande aandeelhouders. Om deze problemen ten volle te kunnen waarderen, dient een stap terug te worden gemaakt naar het oorspronkelijke werk van Modigliani en Miller [11, 12].

De onvrede met het MM model vloeit voort uit de consequentie dat de optimale vermogensstructuur voor honderd procent uit niet-ondernemend vermogen zou bestaan. Robicheck en Myers [13] en Hirshleifer [3] waren de eersten die suggereerden dat het ontbrekende element wel eens de met een faillissement gepaard gaande kosten zou kunnen zijn. Om deze echter formeel in het model op te nemen, moet een tweetal hindernissen worden genomen: allereerst dient het faillissementsrisico te worden geïntroduceerd en vervol. gens dient de kostenconsequentie van een dergelijk faillissement te worden opgenomen. ${ }^{9}$ ) In aanwezigheid van een faillissementsrisico behoeven het maximaliseren van de waarde van de onderneming en het maximaliseren van de welvaart van de bestaande aandeelhouders echter geenszins tot hetzelfde optimum te leiden. De oorzaak daarvan is gelegen in het feit dat onder deze

3) Weliswaar stelten Modigliani en Miller [11] in hun voetnoot 18 dat hun model van kracht blijft in aanwezigheid van het faillissementsrisico, maar een formele uitwerking van die stelling geven zij niet. Zoals het vervolg van de paragraaf hoopt duidelijk te maken, is het juist bij de formele uitwerking, dat de problemen ten aanzien van de achterliggende veronder stellingen naar voren komen. 
omstandigheid zg. „expropriation” effecten kunnen optreden: is het niet-ondernemend vermogen eenmaal verstrekt en liggen de condities vast dan kun. nen latere beslissingen van de ondernemingsleiding resulteren in een waar. dedaling van deze claims. Om dit in te zien dient te worden bedacht dat tal van aanvullende beslissingen kunnen leiden tot een vergroting van het faillissementsrisico en dit terwijl de contractuele beloning voor het dan reeds aanwezige niet-ondernemend vermogen vast ligt. Daardoor kunnen dergelijke beslissingen er in resulteren dat er wel "states of nature" zijn waarin de crediteuren minder ontvangen dan onder de aanvankelijke plannen maar geen ,states of nature" waarin een compenserend "meer" wordt ontvangen. Het gevaar dat dergelijke beslissingen worden genomen, is bovendien reëel omdat het zich laat bewijzen dat de daling van de waarde van het bestaande niet-ondernemend vermogen gepaard gaat met een stijging van de waarde van het ondernemend vermogen. Intuitief laat dit effect zich inzien wanneer bedacht wordt dat de verschaffers van het niet-ondernemend vermogen vis à vis de nieuwe en grotere risico's eigenlijk te weinig betaald krijgen, omdat de betaling nog steeds gebaseerd is op de oorspronkelijke, minder riskante, situatie.

TABEL 1

\begin{tabular}{lllll}
\hline & $\begin{array}{l}\text { Investerings- } \\
\text { bedrag }\end{array}$ & $\begin{array}{l}\text { Opbrengst in } \\
\text { state 1 }\end{array}$ & $\begin{array}{l}\text { Opbrengst in } \\
\text { state 2 }\end{array}$ & $\begin{array}{l}\text { Netto contante } \\
\text { waarde }\end{array}$ \\
\hline A & 100 & 250 & 75 & 30 \\
B & 100 & 275 & 0 & 10 \\
\hline
\end{tabular}

De problemen laten zich illustreren aan de hand van een cijfervoorbeeld waar bij uit twee elkaar wederzijds uitsluitende investeringsmogelijkheden moet worden gekozen. ${ }^{4}$ ) Teneinde neveneffecten uit te sluiten wordt aangenomen dat er geen belastingen of faillissementskosten zijn. Beide investeringen ver. gen een eenmalige uitgave van 100 en leveren over één periode een bepaalde opbrengst die afhankelijk is van de zich dan voordoende „state of nature”; er zijn slechts twee denkbare "states of nature” en de prijs van een "primitive security" ${ }^{\prime \prime}$ is voor elk van deze ,states".4. Tabel 1 bevat de overige gegevens, alsmede de netto contante waarde van de beide projecten gegeven de prijs van de ,primitive securities".

Gezien de netto contante waarden doet de onderneming er goed aan project A te kiezen. Stel voorts dat besloten wordt het benodigde investeringsbe. drag in zijn geheel te lenen. In dat geval moet zij de schuldeisers een bedrag van 175 aan het einde van de periode toezeggen $(.4 \times 175+.4 \times 75=100)$. De

\footnotetext{
4) Talloze andere voorbeelden van „expropriacion” op welhaast elk denkbaar terrein laten zich construeren. Zo wordt in [6], hfst. 4, uitvoerig ingegaan op de gevolgen van een tussentijdse wijziging in de vermogensstructuur.

5) Een "primitive security" kan worden omschreven als cen vermogenstitel op grond waarvan in één bepaalde „state of nature" een bedrag 1 wordt ontvangen, terwijl in alle overige ,states of nature" in het gehee! niets wordt ontvangen. Wan neer wordt aangenomen dat er voor elke denkbare „state of nature" een dergelijk "primitive security" bestaat (of althans is te constwueren), kunnen meer complexe vermogenstirels zoals aandelen en obligaties worden beschreven in termen van portefeuilles van „primitive securities". De waarde van zo'n complexe vermogenstitel laat zich dan bepalen als de som van de waarden van de samenstellende ,primitive securities". Voor een nadere uiteenzeting wordt verwezen naar [6], pag. 5-6.
} 
verschaffers van het niet-ondernemend vermogen gaan accoord en de 100 wordt ter beschikking van de onderneming gesteld.

Wat nu wanneer de onderneming alsnog besluit project $B$ uit te voeren in plaats van project A? De gevolgen zijn weergegeven in tabel 2.

TABEL 2

\begin{tabular}{lllllll}
\hline & $\begin{array}{l}\text { Opbrengst } \\
\text { OV } \\
\text { state } 1\end{array}$ & $\begin{array}{l}\text { Opbrengst } \\
\text { OV in } \\
\text { state 2 }\end{array}$ & $\begin{array}{l}\text { Waarde } \\
\text { OV }\end{array}$ & $\begin{array}{l}\text { Opbrengst } \\
\text { NOV } \text { in }^{6} \\
\text { state 1 }\end{array}$ & $\begin{array}{l}\text { Opbrengst } \\
\text { NOV in } \\
\text { state 2 }\end{array}$ & $\begin{array}{l}\text { Waarde } \\
\text { NOV }\end{array}$ \\
\hline $\begin{array}{l}\text { A wordt } \\
\text { gekozen }\end{array}$ & 75 & 0 & 30 & 175 & 75 & 100 \\
$\begin{array}{l}\text { B wordt } \\
\text { gekozen }\end{array}$ & 100 & 0 & 40 & 175 & 0 & 70 \\
\hline
\end{tabular}

Uit tabel 2 blijkt dat het in het belang van de aandeelhouders is om, wanneer zij de hoofdsom van de lening eenmaal binnen hebben, alsnog te kiezen voor het slechtere project B. De gevolgen worden afgewenteld op de crediteuren die als gevolg van de veranderde keuze met een eenmalig vermogensverlies van 30 worden geconfronteerd. Het laat zich eenvoudig inzien dat de oorzaak is gelegen in de mogelijkheid om failliet te gaan.

Potentiële crediteuren zullen uiteraard trachten zich tegen de hier beschre. ven gevaren te beschermen en in beginsel staan hen hiertoe talloze wegen open. Zo kan met het oog op de toekomstige verhogingen van de „leverage ratio" worden bedongen dat de vorderingen uit hoofde van in de toekomst af te sluiten leningen bij de eigen vordering worden achtergesteld.') Eventuele wijzigingen in investeringsplannen kunnen contractueel aan de goedkeuring van de crediteuren onderhevig zijn. Zelfs kan in theorie zover worden gegaan dat bij beslissingen die in het nadeel van de bestaande crediteuren uitpakken, een aanpassing van de contractuele rente dient plaats te vinden ofwel een schadeloosstelling in enige andere vorm. Ogenschijnlijk lijken er dus geen on overkomelijke problemen op te doemen. Schijn echter, bedriegt ook hier. Om tot de in de vorige paragraaf beschreven resultaten te kunnen komen, zal moeten worden aangenomen dat de overeengekomen clausules een volledige bescherming bieden en juist op dit punt blijken de faillissementskosten veelal roet in het eten te gooien. Bovendien zal moeten worden aangenomen dat er geen kosten gemoeid zijn met het opnemen van beschermende clausules in de leenovereenkomst, met het toezicht op de naleving ervan en met het afdwingen van naleving daar waar wanprestatie dreigt. Voorzichtig uitgedrukt heeft met name deze laatste veronderstelling een schijn van inconsistentie met de veronderstelling dat een eventueel faillissement wel met kosten gepaard gaat. Zelfs wanneer dit laatste niet het geval zou zijn, dan nog lijkt de theorie eerder verder van de werkelijkheid te geraken dan haar beter te benaderen.

Met de introductie van het faillissementsrisico blijkt derhalve het begrip

\footnotetext{
6) $\mathrm{OV}=$ ondernemend vermogen; NOV = niet-ondernemend vermogen.

7) Zie voor een nadere uiteenzeting $[5,6]$.
} 
marktperfectie ineens een heel wat gecompliceerder inhoud te krijgen dan aanvankelijk wellicht vermoed. Anderzijds ligt hier stellig een van de mogelijkheden om een belangrijke uitbreiding aan het model te geven.

\section{Uitbreiding}

Met het voorgaande moge voldoende zijn aangegeven dat aan het neo-klas. sieke basismodel van de vermogensstructuur nogal wat restrictieve veronder. stellingen ten grondslag liggen. Daar komt nog bij dat het maar zeer de vraag is of het beoogde resultaat - een optimale vermogensstructuur met minder dan $100 \%$ niet-ondernemend vermogen - wel wordt bereikt. Het laat zich nl. betwijfelen of de met een faillissement gepaard gaande kosten wel groot genoeg zijn om een belangrijk tegenwicht tegen de belastingbesparingen te kunnen vormen. ${ }^{8}$ ) Is dit niet het geval, dan zou het model weliswaar formeel resulteren in een optimale vermogensstructuur met minder dan honderd procent nietondernemend vermogen, maar hier materieel toch niet voldoende significant van afwijken om de in de praktijk geobserveerde vermogensstructuren bevre. digend te kunnen verklaren.

Dat het model uitbreiding behoeft, moge duidelijk zijn. Een eerste aanknopingspunt kan daarbij worden gevonden in een herbezinning op de voor- en de nadelen van het financieren met niet-ondernemend vermogen. Wanneer rekening wordt gehouden met de belastingheffing aan de zijde van de vermogensverschaffer en met name met het gegeven dat koerswinsten niet, maar rente en dividend wel worden belast, blijkt de uiteindelijke belastingbesparing veelal aanmerkelijk minder groot te zijn. Anderzijds kent de praktijk tal van kosten, die nog niet in het model zijn verwerkt: een belangrijke categorie wordt daarbij gevormd door die kosten die gemaakt moeten worden om de verschaffers van het niet-ondernemend vermogen te beschermen tegen de omschreven „expropriation” effecten. Omdat een volledige bescherming bovendien in de praktijk veelal onhaalbaar (of te kostbaar) zal blijken te zijn, dient tevens rekening te worden gehouden met eventueel optredende „opportunity losses". $\left.{ }^{9}\right)$

Nochtans zullen deze uitbreidingen slechts een eerste stap kunnen zijn. Informatie is in de praktijk kostbaar en bovendien meestentijds onvolledig. De theorievorming op dit terrein staat nog in de kinderschoenen, maar het wordt steeds duidelijker dat ook deze aspecten doorwerken in de opbouw van het vermogen. $\left.{ }^{10}\right)$ Daarenboven zijn er tal van andere zaken zoals heterogene verwach. tingen, institutionele regelingen en beperkingen enz. waarmee in het model nog geen rekening wordt gehouden."

\footnotetext{
8) Zie voor deze kritiek o.a. Jensen en Meckling [4], Wamer [15], Miller [10] en Haugen en Senbet [2].

9) Een uitvoerige theoretische beschouwing hierover is te vinden bij Jensen en Meckling [4].

10) Zie o.a. Leland en Pyle [8], Ross [14] en Franke [1].

11) Een geheel andere inhoud van het in par. 2 beschreven model kan bovendien worden verkregen door $C$ te beschou. wen als de contante waarde van de opportuniteitskosten die voortvloeien uit het nastreven van andere doelstellingen dan alleen het maximaliseren van de welvaart van de bestaande aandeelhouders. Zo breken bijv. Lemer en Rappaport [9] een lans voor de gedachte dat naast een $z o$ hoog mogelijke netto contante waarde van de te entameren investeringsprojecten ook het volgtijdelijk verloop van de te rapporteren boekhoudkundige winst een rol speelt bij de beslissingen van de onder nemingsleiding. Het bereiken van dergelijke (neven)doeleinden, waarbij tevens kan worden gedacht aan zaken als werkgelegenheid, groei, marktaandeel enz., kan in een aantal gevallen negatief worden beinvloed door de mate van "financial leverage". In [7] wordt een poging gedaan aan te geven hoe deze aspecten in het model zouden kunnen worden opgenomen.
} 
De werkgelegenheid van hen die zich met de problematiek van de vermogensstructuur bezig houden lijkt derhalve verre van in gevaar te zijn. Een van de aardigste kanten is daarbij dat men bij een groot aantal van deze uitbreidingen zo niet alle kan blijven denken in termen van het in paragraaf 2 be schreven basismodel, zij het dat de voor- en nadelen een andere inhoud krij. gen. De oplossingsstructuur kan echter dezelfde blijven, het probleem is gelegen in het vlak van de interpretatie. Voorlopig lijkt de voornaamste vraag dus toch hoe het konijn in de hoed te krijgen.

\section{Literatuur}

1. G. Franke Information, property rights and the theory of corporate finance, nota gepresenteerd tij. dens de Nijenrode Conference on Financial Management of Corporate Resource Allocations, Breu. kelen NL, 7.10 augustus 1979.

2. R. A. Haugen and L. W. Senbet - The insignificance of bankruptcy costs to the theory of optimal capital structure, Joumal of Finance XXVII, mei 1978, pag. 383.393

3. J. Hirshleifer Investment, interest and capical, Prentice Hall, Englewood Cliffs, N.J. 1970.

4. M. C. Jensen and W. H. Meckling . Theory of the firm: Managerial behaviour, agency costs and ownership structure, Joumal of Financial Economics 3, no. 4, ]976, pag. 305.360.

5. M. J. L. Jonkhart - De achtergestelde lening nader bekeken, Bank en Effectenbedrijf 28, juli/augustus 1979, pag. 251.256.

6. M. J. L. Jonkhart Optimal capital structure and corporate debt capacity, academisch proefschrift, Rotterdam 1980.

7. M. J. L. Jonkhart Taxable income and financial leverage, nota gepresenteerd tijdens de 7e Annual Meeting van de European Finance Association te Graz (Au), 11.13 september 1980.

8. H. E. Leland and D. H. Pyle Informational asymmetries, financial structure, and financial interme diation, Journal of Finance XXXII, mei 1977, pag. 371.387

9. E. M. Lemer and A. Rappaport Limit DCF in capital budgeting, Harvard Business Review, septem. ber-oktober 1968, opgenomen in: Finance Series Part III, reprint from the Harvard Business Review, pag. 57.63 .

10. M. H. Miller Debt and taxes, Journal of Finance XXXII, mei 1977, pag, 261.275.

11. F. Modigliani and M. H. Miller - The cost of capital, corporation finance and the theory of investment, American Economic Review XLVIII, jumi 1958, pag. 261.297.

12. F. Modigliani and M. H. Miller - Corporation income taxes and the cost of capital: A correction, American Economic Review LIII, juni 1963, pag. 433.443.

13. A. A. Robichek and S. C. Myers - Optimal financing decisions, Prentice Hall, Englewood Cliffs, N.J. 1965.

14. S. A. Ross . The determination of financial structure: The incentive signalling approach, Bell Journal of Economics 8, Voorjaar 1977, pag. 23.40.

15. J. B. Warner Bankruptcy costs: Some evidence, Journal of Finance XXXII, mei 1977, pag. 337-347. 